\title{
Is neonatal hyperinsulinemic hypoglycemia a misnomer?
}

\begin{abstract}
The Pediatric Endocrine Society recommends measuring serum insulin in the evaluation of persistent hypoglycemia in neonates. However, the serum insulin might not be high in cases of hypoglycemia secondary to hyperinsulinism- thus is neonatal hyperinsulinemic hypoglycemia a misnomer.
\end{abstract}

Keywords: hyperinsulinemia, hypoglycemia, neonate, misnomer

\author{
Volume 5 Issue 2 - 202I
}

\section{Shabih Manzar}

Associate Professor, Department of Pediatrics, Louisiana State University of Health Sciences, USA

\author{
Correspondence: Shabih Manzar, Associate Professor, \\ Department of Pediatrics, College of Medicine, Louisiana State \\ University of Health Sciences, I50 I Kings Highway, Shreveport, \\ LA 7||30, Tel 318-626-1623, Fax 318-698-4305, \\ Emailsmanza@lsuhsc.edu
}

Received: October 06, 2020 | Published: April 0I, 202I

\section{Opinion}

Hyperinsulinemia (hyper: excess, over, beyond, exaggerated) connotes with increased serum insulin level. The Pediatric Endocrine Society recommends measuring serum insulin in the evaluation of persistent hypoglycemia in neonates. ${ }^{1}$ However, the serum insulin might not be high in cases of hypoglycemia secondary to hyperinsulinism- thus is neonatal hyperinsulinemic hypoglycemia a misnomer?

The plasmainsulin concentration is affected by its pharmacokinetics. A large fraction of the pancreatic insulin is cleared by the liver at first bypass. Therefore, the insulin concentration measured in peripheral plasma may be up to $90 \%$ lower than the initial peak concentration. ${ }^{2}$ The other caveat is that a complete reference system in conformance with International Organization for Standardization requirements is yet to be established for insulin. ${ }^{3}$

The argument in favor of obtaining serum insulin level during a hypoglycemic episode is as follows. When hypoglycemia happens, the first metabolic response is the total suppression of insulin. Therefore, any detectable level of serum insulin at the time of hypoglycemia can be considered abnormal and should be regarded as evidence of inappropriate insulin secretion. ${ }^{4}$ But the counter argument is: why call it hyperinsulinemia if the level is not high or increased?

We therefore suggest that neonatal hyperinsulinemic hypoglycemia is a misnomer. The best approach in diagnosing neonatal hypoglycemia is to use a combination of low serum glucose, low serum ketone bodies and a positive glucagon stimulation test and not relying on serum insulin level.

\section{Conclusion}

Neonatal hyperinsulinemic hypoglycemia is a misnomer. The best approach in diagnosing neonatal hypoglycemia is to use a combination of low serum glucose, low serum ketone bodies and a positive glucagon stimulation test and not relying on serum insulin level.

\section{Acknowledgments}

None.

\section{Conflicts of interest}

The author declares there is no conflict of interest.

\section{Funding}

None.

\section{Authors' contributions}

I am the solo author of the paper.

\section{References}

1. Thornton PS, Stanley CA, DeLeon DD, et al. Recommendations from the Pediatric Endocrine Society for evaluation and management of persistent hypoglycemia in neonates, infants, and children. $J$ Pediatr. 2015;167(2):238-244.

2. De Leon DD, Stanley CA. Determination of insulin for the diagnosis of hyperinsulinemic hypoglycemia. Best Pract Res Clin Endocrinol Metab. 2013;27(6):763-769.

3. Miller WG, Thienpont LM, Van Uytfanghe K, et al. Toward standardization of insulin immunoassays. Clinical Chemistry. 2009;55(5):1011-1018.

4. Palladino AA, Bennett MJ, Stanley CA. Hyperinsulinism in infancy and childhood: when an insulin level is not always enough. Clinical Chemistry. 2008;54(2):256-263. 